\section{Routine examination of appendices in Hong Kong}

Drs Chan and $\mathrm{Fu}$ made a retrospective study of more than 11000 resected appendices and described a number of relatively rare lesions, some of which had not been suspected clinically. ${ }^{1}$ They estimated that $0.74 \%$ of cases contained clinically important pathological findings which were likely to have been missed had the appendix not been examined histopathologically.

It was surprising that they made no mention of the not uncommon situation in which an appendix is removed, has equivocal macroscopic appearances, but is found microscopically to show gross acute serosal inflammation without evidence of intrinsic inflammatory change. This of course indicates a presence of a pronounced inflammatory focus within the abdomen but outside the appendix. Most of these cases occur in young women with a salpingitis that was not apparent at operation. Such information is surely of help to the clinician in the further management of these patients whose abdominal pain is unlikely to have been relieved by appendicectomy and who often benefit from postoperative antibiotics.

\section{Reference}

1 Chan KW, Fu KH. Value of routine histopathological examination of appendices in Hong Kong. J Clin Pathol 1987;40:429-33.

SB COGHILL Department of Histopathology, Northampton General Hospital, Cliftonville, Northampton NNI 5BD.

Drs Chan and Fu comment:

The comment made by $\mathrm{Dr}$ Coghill is quite valid. We have indeed come across appendices in which clinically important inflammation is present only in the serosa, indicating the presence of an inflammatory focus within the abdomen other than the appendix. Without careful histopathological examination, some of these appendices could be taken to have acute appendicitis on external examination. Similarly, the finding of a perfectly normal appendix in a case of suspected acute appendicitis is also of clinical importance, as this should prompt the clinicians to investigate for a focus of inflammation elsewhere in the abdomen. Negative findings are therefore of definite clinical importance in some cases.
Using our method of study, the appendices showing serosal inflammation alone are mixed with the large group of acute appendicitis as both lesions are indexed by the same code. As a result, we have not been able to separate and study the effects of histopathological examination of this subgroup. The estimated $0.74 \%$ of clinically important pathological diagnoses made on routine histopathology must be taken as a baseline value. More accurate estimates will need further study, with the participation of surgeons.

$$
\begin{array}{r}
\text { KW CHAN } \\
\text { KH FU } \\
\text { Department of Pathology, } \\
\text { Queen Mary Hospital Compound, } \\
\text { Hong Kong. }
\end{array}
$$

\section{Embryonal carcinoma of testis simulating} seminoma

I was interested to read the article by Alderdice and Johnston. ${ }^{1}$ I have looked carefully at the photomicrographs in the article and I can see no tumour which I would diagnose as seminoma, even in the so called "seminoma like areas".

The authors use rather confusing terminology. They start by using the British terminology where "teratoma" implies a wide range of non-seminomatous germ cell tumours, ${ }^{23}$ but quickly change to American/WHO terminology. ${ }^{4}$ No reference is made to the British Testicular Tumour Panel and Registry, and the author's difficulties in differentiating between seminoma and malignant teratoma undifferentiated (MTU/embryonal carcinoma (EC)), may stem from their lack of acquaintance with the British publications. The British Testicular Tumour Panel and Registry $^{23}$ emphasise the similarities between seminoma and MTU in some instances but "points in favour of a teratoma are .... a greater degree of cellular pleomorphism and mitotic activity, and a tendency for the nuclei of the tumour cells to overlap one another ... The seminoma cell nucleus frequently contains a single prominent, rounded, often eosinophilic, nucleolus, which contrasts with the usually dense and hyperchromatic nucleoli, often multiple and of variable size, in the teratoma". ${ }^{2}$

This description clearly excludes a diagnosis of seminoma in a "seminoma like area", especially as fig 2 closely resembles Pugh's figure illustrating a typical teratoma. $^{3}$
It is regrettable that Alderdice \&and Johnston only referred to Amezizcan publications and omitted to include Brrtish publications which would have given $\underset{\square}{\overrightarrow{3}}$ the correct diagnosis.

KM GRTGOR Department of Patho $\overline{\mathbb{P}} g y$ University Medical Sc Pool, Teviot Pgace, Edinburgh EH8 $\frac{\mathrm{g}}{\mathrm{s}} \mathrm{A}$.

References

$\overrightarrow{0}$

1 Alderdice JM, Johnston SR. Embryona $\overrightarrow{\text { țar }}$ cinoma of testis simulating seminoma. JElin Pathol 1987;40:434-7.

2 Collins DH, Pugh RCB. The pathology oftesticular tumours. Br J Urol 1964;36(suppl): 1-112.

3 Pugh RCB. Pathology of the testis. Blackwell: Scientific Publications, 1976.

4 Mostofi FK, Sobin LH. Histological typog of testicular tumours. In: International histological classification of tumours No 16. Geqeva: World Health Organisation, 1977.

\section{Dr Alderdice comments:}

I feel that Dr Grigor concentrates $3_{\text {too }}$ quickly on the fine nuclear detail and nosses the main point behind the publication low power histological examination, of these germ cell tumours bore a borbus stoma containing abundant lympliogtes, and the first case had giant cell granutornata. The tumour cells were arranged for the most part in broad solid islands, and the ifial impression of several consultant patiologists was that the overall pattern appered seminomatous rather than teratomato $\overrightarrow{0}$ in differentiation.

Several of the nuclear points which- $\mathrm{Dr}$ Grigor makes in favour of the diagno teratoma-that is, cellular pleomorphism and mitotic activity-were mentioned if the discussion on diagnosis in the article, oand both the letter writer and ourselves a in complete agreement as to the final diagiosis when the cellular detail is carefully examined.

The aim of this article was to illustratesthe area of overlap between seminoma zand embryonal carcinoma (malignant tera ma undifferentiated), and to point out thangne does have to examine cellular and nuelear detail carefully after noting the overalligattern to reach the correct diagnosis. InNhis latter point we are in complete agreemegnt.

JOAN M ALDERAICE

Northern Area Labord ry, Cushendall R $\mathrm{R}$ ad, Ballymena,

Northern Iretsind. 